УДК 330

\title{
КОМОРБИДНОСТЬ БА С ЗАБОЛЕВАНИЯМИ ССС И ЖКТ
}

\author{
Авчиев Абдулага Тагирбегович \\ студент лечебного факультета \\ ФГБОУ ВО «Дагестанский государственный \\ медицинский университет»
}

Аннотация: В данной статье приводятся результаты исследования и анализ коморбидности БА с патологией ССС и ЖКТ на основании изучения статистических данных, полученных в процессе мониторинга историй болезней пациентов ГКБ 1 и РКБ г. Махачкала в период с 2018 по 2021 гг.

Ключевые слова: бронхиальная астма, кардиопатология, сердечнососудистая система, бронхи, артериальная гипертензия, аритмии, желудочнокишечный тракт, гастроэзофагеальная рефлюксная болезнь.

\section{COMORBIDITY OF BRONCHIAL ASTHMA WITH DISEASES OF THE CARDIOVASCULAR SYSTEM AND GASTROINTESTINAL TRACT}

\section{Avchiev Abdulaga Tagirbekovich}

\begin{abstract}
This article presents the results of a study and analysis of the comorbidity of BA with pathology of the cardiovascular system and gastrointestinal tract based on the study of statistical data obtained during the monitoring of the medical histories of patients of GKB 1 and RKB of Makhachkala in the period from 2018 to 2021.
\end{abstract}

Keywords: bronchial asthma, cardiopathology, cardiovascular system, bronchitis, arterial hypertension, arrhythmias, gastrointestinal tract, gastroesophageal reflux disease.

Бронхиальная астма (БА) является гетерогенным заболеванием, характеризующимся хроническим воспалением дыхательных путей, наличием респираторных симптомов, таких как свистящие хрипы, одышка, заложенность в груди и кашель, которые варьируют по времени и интенсивности, и проявляются вместе с вариабельной обструкцией дыхательных путей. 
Был проведен анализ результатов клинико-анамнестических данных и результатов лабораторных и инструментальных методов исследования и лечения больных бронхиальной астмой с коморбидными заболеваниями по данным отделений пульмонологии, кардиологии, гастроэнтерологии медицинских учреждений г. Махачкала, в результате которого были выявлены особенности протекания БА в сочетании с другими заболеваниями сердечнососудистой системы и верхних отделов пищеварительного тракта.

Огромная социально-экономическая и демографическая значимость заболеваемости БА определяется ее широкой распространенностью среди населения земного шара, в связи с чем ее можно считать проблемой современного здравоохранения. По оценкам ВО3, 235 миллионов человек страдают от бронхиальной астмы. БА регистрируется более чем у 5\% взрослых и почти у 10\% детей. Согласно статистическим данным медицинских организаций г. Махачкала в период с 2018 по 2021 г. ежегодно в среднем регистрируются около 300-400 новых случаев заболевания БА, причем в 45\% случаев БА коморбидна с разного рода заболеваниями сердечно-сосудистой системы и пищеварительного тракта. Среди больных бронхиальной астмой в возрасте до 5 лет количество мальчиков превалирует, затем число девочек становится выше. К 30 годам это соотношение выравнивается. Бронхиальная астма чаще всего сочетается со следующими видами патологии ССС и ЖКТ: гипертоническая болезнь, симптоматическая артериальная гипертензия, ишемическая болезнь сердца, различные виды нарушения сердечного ритма, гастроэзофагеальная рефлюксная болезнь (ГЭРБ), рефлюкс-эзофагит, пептические язвы пищевода, желудка и двенадцатиперстной кишки.Например, снижение кислородной емкости крови при БА ведет к спазму приносящих артериол почечных клубочков, вследствие чего снижается почечный кровоток и клубочковая фильтрация. Результатом ишемии почек является продукция ренина, который превращает ангиотензиноген находящийся в крови в ангиотензин I. Последний в свою очередь под действием ангиотензинпревращающего фактора(АПФ) переходит в ангиотензин II (АТ-II), который обладает выраженным сосудосуживающим действием и стимулирует выработку альдостерона, задерживающего в организме ионы натрия и воду, это приводит к гиперволемии, что еще больше усугубляет ситуацию. Результатом сужения резистивных сосудов и задержки жидкости в организме становится повышение АД.

Известно, что на начальных стадиях БА наблюдается повышение уровня серотонина в крови, который, обладает как бронхоконстрикторным, так 
и вазоконстрикторным действием. Определенную роль в регуляции тонуса сосудов играют простагландины, в частности, ПГЕ 2-альфа обладающий вазоконтрикторным действием, концентрация которого нарастает при прогрессировании БА. Роль катехоламинов в развитии АГ у больных БА также велика, так как продукция адреналина и норадреналина во время приступа удушья увеличивается и продолжает нарастать в течение 6-10 суток после приступа. На сегодняшний день, при оценке гемодинамики в малом круге кровообращения, у пациентов с обострением БА большинство исследователей стремятся оценить состояние правых отделов сердца, ориентируясь на давление в легочной артерии, объем кровотока, размеры и толщину миокарда правого сердца, сосудистое и легочное сопротивление. Имеются данные, что почти у 25\% пациентов, страдающих легочной гипертензией, не наблюдалось гипертрофии правого желудочка, а у трети больных с повышением давлением в легочной артерии в пределах верхних границ нормы была обнаружена гипертрофия правого желудочка сердца. Кроме того, у некоторых пациентов наблюдалось дилатация правых отделов сердца, без признаков гипертрофии при нормальном уровне давления в легочной артерии. Есть предположение, что это связано с развитием аутоиммунных изменений в миокарде в результате гипоксии и инфекционно-воспалительного процесса, что является результатом хронической бронхолегочной патологии.

Что касается патологи ЖКТ, учитывая тот факт, что общая распространенность ГЭРБ среди взрослого населения составляет около 20\%, было выявлено, что частота встречаемости симптомов ГЭРБ у больных с астмой составляет 59,2\%, а распространенность ГЭРБ по данным pH-мониторирования пищевода $50,9 \%$, частота эзофагита-37,3\%, грыж пищеводного отверстия диафрагмы 51,2\%.

Согласно данным полученным в ходе научного исследования, проведенного в ГКБ 1 и РКБ г. Махачкала, морфологические, функциональные и структурные изменения в ССС у пациентов, страдающих БА проявляются в виде легочной гипертензии в 53,2\%, гипертрофии и дилатации правого сердца в 43,7\%, причем правого предсердия в 67,8\%, а правого желудочка в 23,2\% случаев. При БА в организме развивается гипоксемия, которая приводит к полицитемии с увеличением гематокрита до 70\%, вследствие чего вязкость крови увеличивается. Согласно проведенному исследованию, именно повышение вязкости крови увеличивает сопротивление току крови по легочным сосудам и способствует увеличению нагрузки на правые отделы сердца. Все эти изменения в сочетании с БА приводят к изменению 
реологических свойств крови и развитию синдрома повышенной вязкости. Ocобое внимание заслуживает тот факт, что вязкость крови может увеличиваться у больных БА и при изменении агрегационных свойств эритроцитов. Почти все авторы, которые изучали этот вопрос у больных с БА указывают на повышение агрегации эритроцитов. У пациентов, страдающих БА в связи с воспалением наблюдается резкое увеличение грубодисперсных белков таких, как фибриноген, С-реактивный белок, глобулины, которые заряжены положительно. В свою очередь, эти белки адсорбируются на отрицательно заряженной мембране эритроцитов, тем самым вызывая снижение отрицательного заряда на мембране эритроцитов и снижая суспензионную стабильность крови. Еще одним из основных свойством эритроцитов является их способность к деформации, т.е. способность изменять свою форму при взаимодействии друг с другом или с просветом капилляра, которая зависит, как считают многие исследователи, с эластичностью мембраны и внутреннего содержимого клетки. Снижение способности эритроцитов к деформации при БА связывают гипоксией, ацидозом и полиглобулинемией. На начальных стадиях БА наблюдается функциональная недостаточность, а затем грубые морфологические изменения эритроцитов. Это проявляется ухудшением деформационных свойств эритроцитов.

При длительно прогрессирующей БА наблюдается функциональная несостоятельность тромбоцитов, нарушение их агрегационных свойств. При этом наступает необратимая агрегация и адгезия, результатом которой является «вязкий метаморфоз» тромбоцитов. В результате этого в кровь выбрасываются различные биологически активные вещества, что является «пусковым механизмом» для хронического внутрисосудистого микросвёртывания крови, что увеличивает вязкость крови.

Помимо вышеперечисленных нарушений морфологических, функциональных и реологических свойств, на основании проведенного статистического анализа выявлено, что при БА, примерно в 29\% случаев встречаются нарушения сердечного ритма. БА чаще сочетается с синусовой тахикардией, желудочковой и предсердной экстрасистолией, a также с мерцательной аритмией. Причем случаи аритмии учащаются во время обострения основного заболевания, т.е. во время приступов БА.

Еще в $1970 X$ годах было доказано, что гипоксемия, вызванная у больных БА, способствует развитию различных нарушений ритма сердца. Из-за снижения количества кислорода в артериальной крови наблюдается гипоксия миокарда, что ведет к электрической неустойчивости миокарда, что, 
следовательно, вызывает различные варианты аритмий. Кроме того, гипоксемия способствует активации симпатоадреналовой системы, которая вызывает повышение норадреналина в крови, в результате его выброса нервными окончаниями. Норадреналин вызывает увеличение автоматизма клеток миокарда, что ведет к появлению эктопических очагов водителей ритма.

Еще одну важную роль в развитии аритмий при БА играет легочная гипертензия, при которой наблюдается перегрузка правых отделов сердца. Резкая перегрузка правого сердца во время обострения БА может стать причиной появления эктопических очагов водителя ритма. Со временем, с каждым обострением БА наблюдается легочная гипертензия, которая ведет к гипертрофии правого сердца, а гипоксемия, в свою очередь, вызывает дистрофические изменения в миокарде, в результате всего этого наблюдается электрофизиологическая неоднородность миокарда, на фоне которой развиваются различные виды аритмий.

Кроме всего сказанного выше, в развитии нарушения сердечного ритма большую роль играют такие препараты, как метилксантины и адреномиметики, которые применяются в лечении БА. Известно, что эуфиллин вызывает тахикардию и может привести к желудочковым экстрасистолам.

Еще одной характерной особенностью ССС при БА является изменение диаметра аорты, размеров левого предсердия и соотношения ДА/ЛП. Так в исследовании, проведенном в пульмонологическом отделении ГКБ 1, было обнаружено, что среди больных с нестероидзависимой БА не зависимо от периода болезни, не обнаружено изменение диаметра аорты. В отличие от диаметра аорты, размеры ЛП отличались в период обострения (немного увеличивались). А вот, среди больных с стероидзависимой БА, были обнаружены увеличение размеров ЛП и уменьшение показателей ДА/ЛП. Эти результаты позволяют полагать, что при увеличении тяжести течения БА имеет место увеличение размера ЛП и соотношения ДА/ЛП.

Вместе с тем состояние больных БА ухудшается наличием гипертрофии левого желудочка преимущественно по эксцентрическому типу. При этом наблюдаются диастолическая дисфункция ЛЖ. Причем основными факторами, приводящими к диастолической дисфункции, являются возраст больного в $2 \%$ случаев, снижение ОФВ1 в 9\% и увеличение сопротивляемости дыхательных путей в $20 \%$ случаев.

По результатам анализа клинических случаев также было выявлено, что гипертрофия ЛЖ и диастолическая дисфункция были выявлены у всех групп пациентов, но частота была больше в группе с сочетанными патологиями. В тех 
группах где была выше тяжесть БА частота гипертрофии и диастолической дисфункции миокарда была выше.

\section{Список литературы}

1. Верткин А. Л., Румянцев М. А., Скотников А. С. Коморбидность // Клиническая медицина. - 2012. - № 10. - С. 4-11.

2. Гаврисюк В. К. Нарушение сердечно-сосудистой системы у больных бронхиальной астмой // Украинский пульмонологический журнал. 2000. - № 2 (Доп.) - С. 31-33.

3. Авчиев А. Т. Особенности кардиопатологии у больных БА в РД по результатам анализа статистических данных медицинских учреждений г. Махачкала // Молодежная наука как фактор и ресурс опережающего развития 2020, c. $243-248$

4. Волков В. Г. Бронхиальная астма и артериальная гипертония // Терапевтический архив. - 1985. - Т. 57, № 3. - С. 53-54.

5. Алексеенко 3. К. Особенности клинического течения и диагностики ИБС на фоне хронических обструктивных заболеваний легких: автореф. дис. ... д-ра мед. наук. - Днепропетровск, 1991. - 30 с.

(C) А.Т. Авчиев, 2021 